\title{
MOVILIDAD SOCIAL INTERGENERACIONAL Y BIENESTAR INDIVIDUAL: EVIDENCIA EMPÍRICA DEL CASO BOLIVIANO
}

\author{
Ricardo Nogales Carvajal, Pamela Córdova Olivera y Manuela Puente Beccar
}

\section{RESUMEN}

La movilidad social intergeneracional tiene una relación estrecha con el bienestar de un individuo. Sin embargo, la identificación de la fuerza de esta relación es muy compleja a razón, entre otros, de la complejidad misma del concepto de bienestar. El presente estudio aporta a la comprensión de esta relación en el caso boliviano, tomando en cuenta un concepto más amplio de bienestar individual que el ingreso/salario, el nivel de educativo o el status ocupacional, considerados como más tradicionales y que han guiado importantes estudios anteriores. A partir de la Encuesta de Movilidad y Estratificación Social (EMES-2009) realizada por PNUD Bolivia, que alimenta un modelo factorial basado en el Enfoque de Capacidades de Sen, se identifican dos aspectos complementarios del bienestar individual: la capacidad para el bienestar material y la capacidad para el bienestar subjetivo. Luego de construir métricas para ambos aspectos, se identifican algunos de sus determinantes, en base al Enfoque de Igualdad de Oportunidades de Roemer, con especial énfasis en el impacto que tienen algunas características del hogar de origen de los individuos, como la escolaridad del jefe, la de su cónyuge, el estilo de vida que ofrecía y la percepción de la clase social en el que se encontraba. Se presentan resultados contrastados para individuos en zonas urbanas y en zonas rurales del país, dando cuenta de rica y novedosa información cuantitativa sobre el grado de movilidad social intergeneracional en el país.

Palabras Clave: Movilidad Social Intergeneracional, Enfoque de Capacidades, Igualdad de Oportunidades, Análisis Factorial. 